Check for updates

London School of Hygiene and Tropical Medicine, UK

Cite this as: BMJ 2021;375:n2485 http://dx.doi.org/10.1136/bmj.n2485 Published: 13 October 2021

\section{The UK government tested the response to a coronavirus-why are we only discovering this now?}

\author{
If we don't seem to have learnt much from Exercise Alice, what can we learn from attempts to conceal \\ it?
}

\section{Martin McKee professor of European public health}

The official inquiry into the UK's handling of the covid-19 pandemic will have many things to consider. This week, another item was added to that list. Previously, it seemed that one reason the response was so problematic was that when ministers dusted off the plans for a pandemic all they had was one for influenza. Matt Hancock, the former secretary of state for health and social care, said as much when asked by MPs, replying, "Famously, all the preparations and the plans that were in place were for a flu pandemic."1 Indeed the Department of Health and Social Care had invoked this argument to justify its failure to act on recommendations from the previously secret report of 2016's Exercise Cygnus, which tested the response to an influenza pandemic and highlighted many weaknesses in the UK's preparedness.

Yet, with the utmost reluctance, the department has now conceded that that was not exactly true. In 2016, Public Health England had undertaken Exercise Alice, a one day table top exercise to identify challenges to managing any cases reaching Britain of another coronavirus, MERS-CoV, thought to have originated in the Arabian Peninsula and which had caused major outbreaks in some other countries, in particular South Korea. ${ }^{2}$ Now, after persistent efforts by an NHS doctor, Moosa Qureshi, the partially redacted report of that exercise has been released. ${ }^{2}$ Its release followed Qureshi's warning that he would appeal PHE's refusal to release it to the Information Commissioner, challenging PHE's argument that publication "could precipitate unnecessary heightened public concern that could lead to loss of public confidence in the government's and the NHS's covid-19 response."

Does this matter? It is possible to argue that the report's recommendations were not especially relevant to covid. MERS and covid-19 are both caused by coronaviruses, but ones that behave quite differently. Covid is much more transmissible and, crucially, is spread by people who are asymptomatic.

Yet, many of its recommendations do seem applicable. For example, the report raised the matter of checks at borders, worryingly noting that "the participants did not find an answer to this and recommended that it required more exploration." Yet SAGE did not discuss border control measures until 28 April 2020 and restrictions were only introduced on 8 June $2020 .^{3}$

Contact tracing and isolation was another area where clarity was lacking and "terminology was used interchangeably." The report continues, "The group did not resolve the quarantine/self-isolation issue."
It recommended an assessment of the costs and benefits of different regimes for cases and contacts. Yet, when the covid pandemic came there was a long delay, to 28 May 2020, before the test and trace service was launched and even now many questions remain about its performance. From the beginning, support for isolation, highlighted as a problem in the report, has been a particular weakness.

Another matter raised was use of personal protective equipment, with concerns about whether patient facing staff had proper training and whether supplies were adequate. It seems superfluous to note that this doesn't seem to have been followed up.

It is possible that some of the other recommendations were acted on. For example, calls for a paper that brought together lessons from South Korea's experience may have been heeded and the paper written. If so, it could take another monumental effort to obtain it. The UK does have excellent community surveys, React and the Office for National Statistics' covid infection studies, but how much they owe to Exercise Alice is unclear.

If we don't seem to have learnt much from Exercise Alice, what can we learn from the attempts to conceal it?

There are legitimate grounds for withholding some documents on measures to counter threats to health. These include measures against hostile activity such as cyber attacks-the WannaCry attack, believed to have originated in North Korea, disrupted large parts of the NHS in 2017. Similarly, we would expect that the government would withhold details of measures against organised crime or corruption, both activities that pose serious threats to health.

Yet, it's hard to accept the argument that the report's publication could have damaged public confidence, at least not any more than many other things-from Dominic Cummings's trip to Barnard Castle to the seemingly endless procurement scandals. ${ }^{4}$ And if the report had been published, there would have been pressure to respond to its recommendations, not least from the Commons Health Select Committee which worked hard to hold ministers to account.

There is a long history of secrecy being used to conceal political and administrative failures and the determined efforts to prevent the report of Exercise Alice seeing the light suggest that little has changed. Indeed, it may be even worse and British newspaper editors have written collectively to demand an inquiry into a newly created clearing house in the Cabinet 
Office that, despite ministerial protestations, is widely viewed as reducing transparency. ${ }^{5}$

The fact that the report's recommendations seem to have been largely ignored is no surprise. It is widely recognised that large parts of government were dysfunctional and that many of the weaknesses in the UK's governance arrangements revealed by Brexit have, if anything, got worse. ${ }^{6}$

In May 2020, I and others called for a rapid inquiry that could learn lessons from the first wave of the pandemic. ${ }^{7}$ That did not happen and mistakes continued to be made. Now, the UK prime minister Boris Johnson has conceded that there must be one, following pressure from bereaved families. He seems in no hurry to find out what it has to say, however. ${ }^{8}$ It won't start until spring 2022, a delay Jeremy Farrar, a government adviser, has described as a disgrace. When it does convene, it will have much to discuss.

The prime minister views himself as a historian. Perhaps he has forgotten that Richard Nixon's downfall after Watergate owed as much to the cover up as to the act itself.

Competing interests: MMK is a member of Independent SAGE.

1 Dyer C. Pandemic preparedness: UK government kept coronavirus modelling secret. BMJ 2021;373:n1501. doi: 10.1136/bmj.n1501 pmid: 34117008

2 lacobucci G. UK was advised to stockpile PPE and screen travellers in 2016 after coronavirus modelling. BMJ 2021;375.

3 Home Office preparedness for covid-19 (coronavirus): management of the borders. https://publications.parliament.uk/pa/cm5801/cmselect/cmhaff/563/56306.htm.

4 Government publishes 40 PPE contracts totalling $£ 4.2 \mathrm{bn}$-a year late. https://goodlawproject.org/news/gov-publishes-40-ppe-contracts.

5 Newspapers concerned over government's FOI process. BBC News. www.bbc.co.uk/news/uk55988252.

6 Jarman H, Greer SL, McKee M. Brexit is just a symptom: the constitutional weaknesses it reveals have serious consequences for health. J Public Health (Oxf) 2020;42:778-83. doi: 10.1093/pubmed/fdz180 pmid: 31927582

$7 \quad$ McKee M, Gill M, Wollaston S. Public inquiry into UK's response to covid-19. BMJ 2020;369:m2052. doi: 10.1136/bmj.m2052 pmid: 32444349

$8 \quad$ McKee M. What went wrong in the UK's covid-19 response?BMJ2021;373:n1309. doi: 10.1136/bmj.n1309 pmid: 34031098

This article is made freely available for use in accordance with BMJ's website terms and conditions for the duration of the covid-19 pandemic or until otherwise determined by BMJ. You may use, download and print the article for any lawful, non-commercial purpose (including text and data mining) provided that all copyright notices and trade marks are retained. 